\title{
The effects of a dietary excess of leucine on the synthesis of nicotinamide nucleotides in the rat
}

\author{
BY BAHIELDIN I. MAGBOUL* AND DAVID A. BENDER ${ }^{\dagger}$ \\ Courtauld Institute of Biochemistry, The Middlesex Hospital Medical School, \\ London WIP $7 P N$
}

(Received 16 August 1982 - Accepted 14 December 1982)

1. In order to test the suggestion that a dietary excess of leucine may be a precipitating factor in pellagra, rats were fed on diets that provided $15 \mathrm{~g}$ leucine $/ \mathrm{kg}$ in excess of requirements for 7 weeks from weaning. This led to a significant reduction in the concentrations of nicotinamide nucleotides in liver and blood. The effect was only apparent when the diets provided less than a minimally adequate amount of nicotinamide, so that the animals were dependent on the synthesis of nicotinamide nucleotides from tryptophan to meet all or part of their requirements.

2. Urinary excretion of $\mathrm{N}^{1}$-methyl nicotinamide was not a useful indicator of tissue concentrations of nicotinamide nucleotides, and seemed not to be adequately sensitive to differentiate between minimal adequacy and marginal deficiency, as demonstrated by changes in concentrations of nicotinamide nucleotides in liver and blood.

3. The addition of leucine to incubation media for the measurement of enzyme activity in tissue homogenates at concentrations within the physiological range, led to a significant activation of tryptophan oxygenase (L-tryptophan: oxygen oxidoreductase (decyclizing), EC 1.13.11.11) and significant inhibition of kynureninase (L-kynurenine hydrolase, EC 3.7.1.3). The effect on tryptophan oxygenase may not be physiologically significant, in view of the considerable range of activity of this enzyme under normal conditions. However, the inhibition of kynureninase, which was primarily competitive with respect to the substrate, probably is physiologically significant, and was enough for this enzyme to become a probable rate-limiting step in tryptophan metabolism and nicotinamide nucleotide synthesis. Other enzymes of the tryptophan - nicotinamide nucleotide pathway were not affected by the addition of leucine to the incubation medium.

4. Feeding $15 \mathrm{~g}$ leucine $/ \mathrm{kg}$ diet in excess of minimum requirements had no effect on the activities of tryptophan oxygenase or kynureninase in liver homogenates. This may reflect the reversible competitive nature of the in hibition of kynureninase by leucine, and hence be an artefact of the incubation procedure. Rats fed on the high-leucine diets excreted significantly more kynurenine than did control animals, which is evidence of inhibition of kynureninase in vivo.

5. It appears that a dietary excess of leucine, of the order of $15 \mathrm{~g} / \mathrm{kg}$ above requirements, may be a precipitating factor in pellagra when there is reliance on the synthesis of nicotinamide nucleotides from tryptophan to meet a part or all of the requirements, but not when minimally adequate niacin is available from the diet.

Pellagra continues to be a major nutritional problem in many countries, and indeed there appears to have been a resurgence of this deficiency disease in recent years in countries from which it was believed to have been eradicated (Ermolieff \& Grosshaus, 1979). It is common not only among people whose dietary staple is maize, the traditionally pellagragenic cereal, but also among Indians whose dietary staple is jowar (Sorghum vulgare). Gopalan \& Srikantia (1960) noted that the tryptophan content of jowar was as high as that of rice, a cereal that is not associated with pellagra, and suggested that a major factor in the pellagragenicity of jowar might be its relatively high content of leucine. Further studies from the Indian Institute for Medical Research in Hyderabad have apparently confirmed the pellagragenic action of leucine. Gopalan et al. (1969) induced black tongue disease (the canine equivalent of pellagra) by manipulating the leucine content of the diets fed to dogs, and Belavady \& Udayasekhara Rao (1979) showed a correlation between the leucine

\footnotetext{
* Present address: Food Research Centre, PO Box 213, Khartoum North, Democratic Republic of The Sudan.

$\dagger$ For reprints.
} 


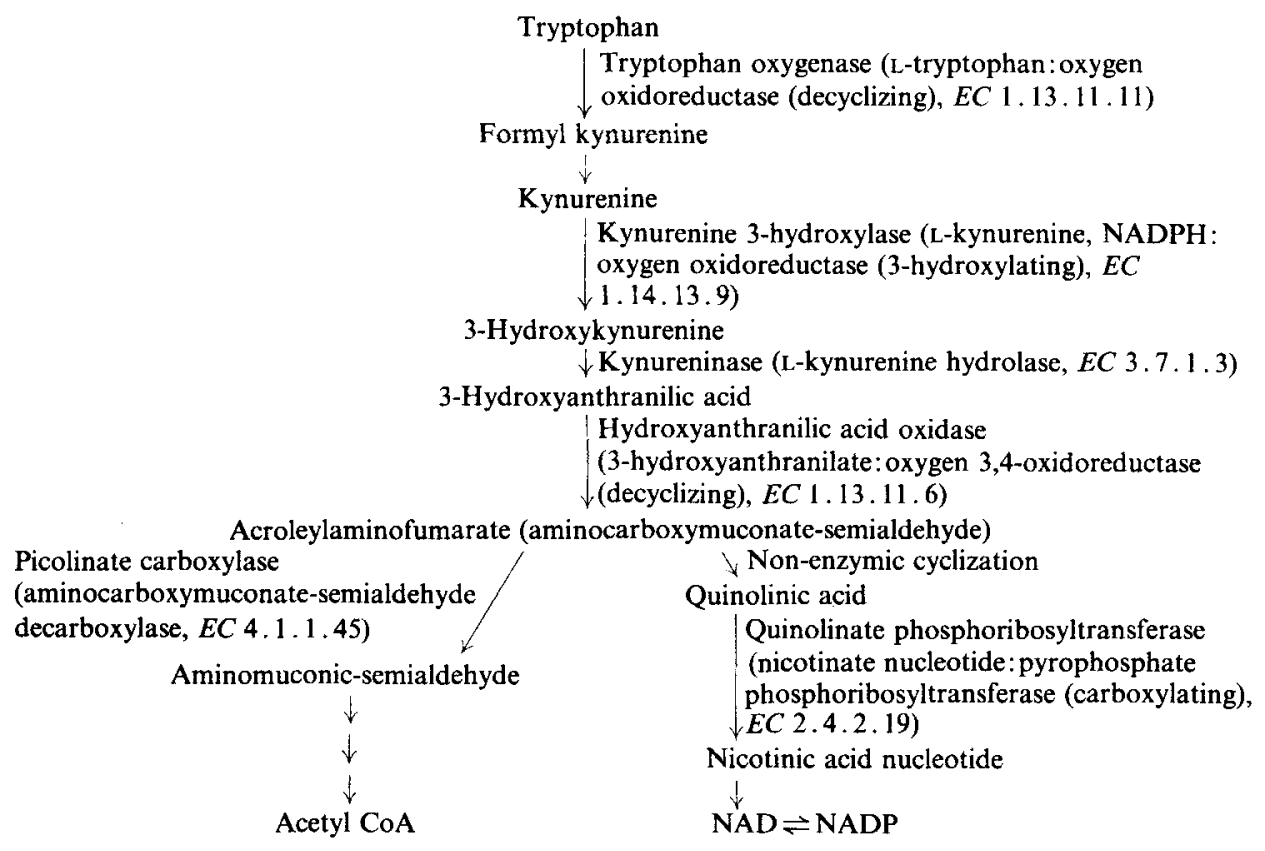

Fig. 1. Enzymes of the oxidative pathway of tryptophan metabolism.

content of different cultivars of jowar and the induction of black tongue disease. Belavady \& Udayasekhara Rao (1973) produced niacin deficiency in monkeys by feeding an excess of leucine, and similar effects have been shown in rats (Bapu Rao et al. 1975).

Yamada et al. (1979) confirmed that a dietary excess of leucine leads to depletion of tissue nicotinamide nucleotides in the rat, but other workers (Nakagawa et al. 1975; Manson \& Carpenter $1978 a, b$ ) have been unable to demonstrate any effect of a dietary excess of leucine on niacin nutritional status in man, rats, chicks or dogs.

The present study was undertaken in order to determine whether or not an excess of leucine in the diet can precipitate pellagra. Rats were fed on diets that provided only minimally adequate amounts of tryptophan or nicotinamide or both to meet their requirements, and the blood and liver concentrations of nicotinamide nucleotides and the urinary excretion of $\mathrm{N}^{\mathrm{I}}$-methyl nicotinamide were measured as indices of niacin nutritional status. The results confirm the hypothesis proposed by Gopalan \& Srikantia (1960) that under these conditions an excess of leucine is pellagragenic, and that leucine inhibits the oxidative metabolism of tryptophan (Fig. 1) and hence the synthesis of nicotinamide nucleotides from tryptophan, inhibiting kynureninase (L-kynurenine hydrolase, EC 3.7.1.3) competitively with respect to its substrate.

\section{METHODS}

\section{Animals and diets}

Male Wistar rats bred in the Courtauld Institute of Biochemistry were used; they were weaned on to the experimental diets at $21 \mathrm{~d}$ after birth, and maintained on these diets for up to 7 weeks. Five animals received each diet; they were housed together, in grid-based cages to minimize coprophagy, with unrestricted access to food and water at all times. Urine was collected over the $24 \mathrm{~h}$ before killing; for this animals were housed individually in stainless-steel metabolism cages (Acme Metal Co., Chicago, Ill.). 
Table 1. Composition of experimental diet $(\mathrm{g} / \mathrm{kg})$

\begin{tabular}{lcc} 
Maize meal & 580 \\
& Vitamin-free casein & 35 \\
& Gelatine & 60 \\
& Maize oil* & 25 \\
& Amino acid mixture & \\
& Mineral salt mixture & $9 \cdot 2$ \\
& 41 \\
& Vitamin mixture & 2 \\
& Sucrose & to $1 \mathrm{~kg}$ \\
\hline
\end{tabular}

Additions of tryptophan, nicotinamide and leucine at the expense of sucrose were made as shown in Table 2.

* The following were dissolved in the maize oil to provide $(/ \mathrm{kg} \mathrm{diet})$; retinyl palmitate $10 \mathrm{mg}$, cholecalciferol $3 \mu \mathrm{g}$, menaphthone $1 \mathrm{mg}, \alpha$-tocopheryl acetate $75 \mathrm{mg}$.

$\dagger$ The amino acid mixture provided $(\mathrm{g} / \mathrm{kg}$ diet $)$ : methionine $2 \cdot 25$, isoleucine $1 \cdot 70$, threonine $1 \cdot 50$, lysine $1 \cdot 49$, valine $1 \cdot 10$, cystine $1 \cdot 00$, tryptophan $0 \cdot 13$; this diet provided a total of $900 \mathrm{mg}$ tryptophan $/ \mathrm{kg}$ and essentially no nicotinamide.

$\ddagger$ The mineral salt mixture provided (/ $\mathrm{kg}$ diet): $\mathrm{CaHPO}_{4} 18 \mathrm{~g}, \mathrm{CaCO}_{3} 4.5 \mathrm{~g}, \mathrm{KCl} 8.2 \mathrm{~g}, \mathrm{Na}_{2} \mathrm{HPO}_{4} 7.4 \mathrm{~g}$, $\mathrm{MgSO}_{4} \cdot \mathrm{H}_{2} \mathrm{O} 2 \cdot 8 \mathrm{~g}, \mathrm{MnSO}_{4} \cdot 4 \mathrm{H}_{2} \mathrm{O} 361 \mathrm{mg}$, ferric citrate. $5 \mathrm{H}_{2} \mathrm{O} 349 \mathrm{mg}, \mathrm{ZnCO}_{3} 60 \mathrm{mg}, \mathrm{CuSO}_{4}, 5 \mathrm{H}_{2} \mathrm{O} 47 \mathrm{mg}, \mathrm{KIO}_{3}$ $2 \mu \mathrm{g}$.

\$ The vitamin mixture provided ( $/ \mathrm{kg}$ diet): choline bitartrate $1.8 \mathrm{~g}$, calcium pantothenate $40 \mathrm{mg}$, thiamin hydrochloride $10 \mathrm{mg}$, riboflavin $10 \mathrm{mg}$, folic acid $5 \mathrm{mg}$, pyridoxine hydrochloride $1.2 \mathrm{mg}$, biotin $1 \mathrm{mg}$, cyanocobalamin $50 \mu \mathrm{g}$, glucose to $2 \mathrm{~g}$.

Rats were killed by decapitation, and blood was collected into heparinized vessels on ice. Tissues were dissected out and frozen in liquid nitrogen within 45-60 s of killing. For the measurement of nicotinamide nucleotide concentrations, tissue was kept in liquid $\mathrm{N}_{2}$ for up to $1 \mathrm{~h}$ before analysis; for the measurement of enzyme activities tissue was stored at $-20^{\circ}$ until required. Preliminary studies (Bender, $1980 a$ and unpublished observations) showed that such storage for up to 4 weeks has no effect on the activity of any of the enzymes measured.

The diets used were based on that described by Carter et al. (1977). As shown in Table 1, the diet was based on maize, gelatine and sucrose, with a small amount of vitamin-free casein and a mixture of essential amino acids to supplement the protein of the maize and gelatine. It provided $10.3 \mathrm{MJ}$ metabolizable energy $/ \mathrm{kg} ; 25 \%$ from protein (including gelatine) and free amino acids, $18 \%$ from fat and $57 \%$ from carbohydrate. The basal diet provided an inadequate amount of tryptophan to permit the synthesis of nicotinamide nucleotides and essentially no available niacin. Preliminary studies (B. I. Magboul, unpublished results) showed that the provision of $4 \mathrm{mg}$ nicotinamide, a total of $1030 \mathrm{mg}$ tryptophan (130 mg in addition to the basic diet shown in Table 1) or $980 \mathrm{mg}$ tryptophan ( $80 \mathrm{mg}$ in addition to the basic diet) together with $1.5 \mathrm{mg}$ nicotinamide $/ \mathrm{kg}$ diet was just adequate to permit the growth of weanling rats and to permit sustained growth over 7 weeks, albeit at a slower rate than when animals were fed on the animal-house stock diet (diet 86; E. Dixon \& Sons, Ware, Herts). As shown in Table 2, these minimally adequate amounts of tryptophan or nicotinamide or both were used to formulate three sets of diets: diet A provided for nicotinamide nucleotide synthesis from both tryptophan and nicotinamide with neither precursor alone provided in adequate amount; diet B provided minimally adequate nicotinamide without the need for synthesis from tryptophan; diet $\mathrm{C}$ provided adequate tryptophan and no preformed niacin. Leucine $(15 \mathrm{~g} / \mathrm{kg})$ was incorporated in the diets at the expense of sucrose, as shown in Table 2 , to provide $15 \mathrm{~g} / \mathrm{kg}$ diet in excess of that present in the diet described by Carter et al. (1977) as being adequate to permit limited growth for a bio-assay of available niacin.

As described previously (Bender et al. 1982), the diets were prepared by mixing the dry 


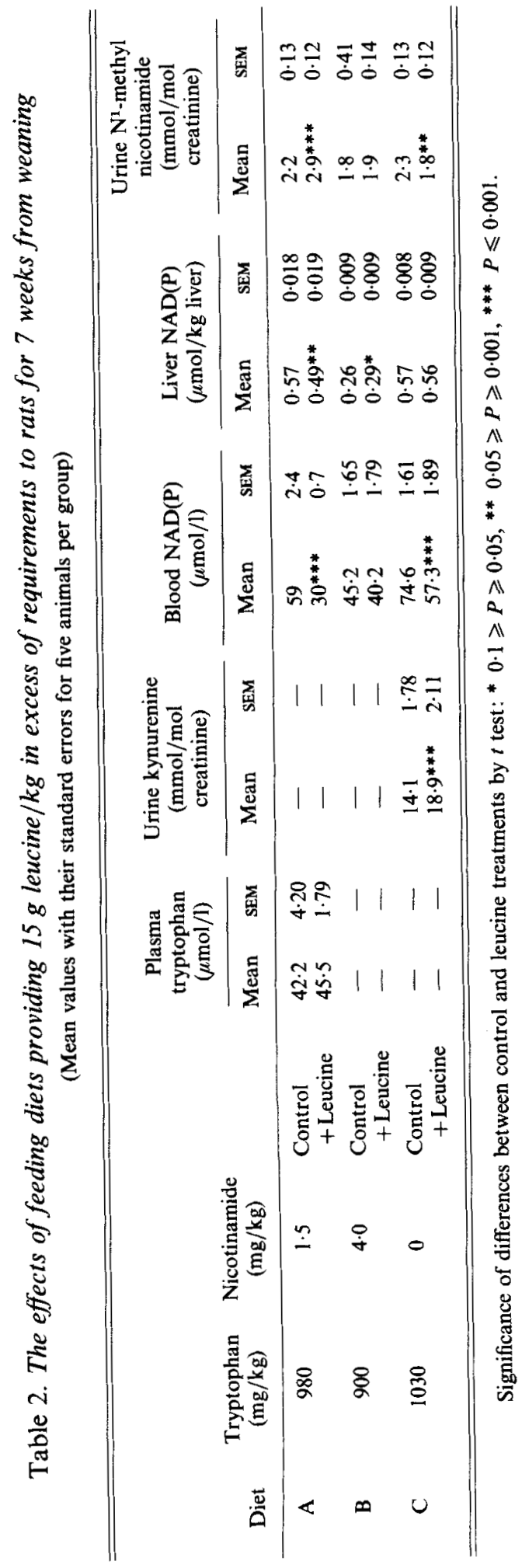


ingredients, apart from the gelatine, with the oil in the usual way, and then dissolving the gelatine in warm water $(100 \mathrm{~g} / 1)$ and mixing with the dry ingredients to produce a stiff paste, which set to a firm jelly on cooling. This permitted ready addition of small quantities of tryptophan and nicotinamide to the diets, minimized the problems of blockage of the urine-faeces separators of the metabolism cages that may occur when powdered diets are used, and seemed to be well accepted by the animals.

\section{Analytical methods}

Tissue and blood concentrations of total nicotinamide nucleotides (the sum of $\mathrm{NAD}^{+}$, $\mathrm{NADP}^{+}, \mathrm{NADH}$ and NADPH) were determined fluorimetrically by the modification of the methods of Kaplan et al. (1951) and Lowry et al. (1961) that has been described previously (Bender et al. 1982). Liver samples were analysed within $1 \mathrm{~h}$ of killing, after storage in liquid $\mathrm{N}_{2}$, since preliminary studies (B. I. Magboul, unpublished results) showed that even in liquid $\mathrm{N}_{2}$ there was significant loss on storage for longer than approximately $6 \mathrm{~h}$. Portions of heparinized whole blood $(200 \mu \mathrm{l})$ were mixed with dilute hydrogen peroxide, then acid sodium sulphate and boiled within 1 min of killing the animals; although analyses were then normally performed immediately, preliminary studies (B. I. Magboul, unpublished results) showed that under these conditions samples could be stored at $4^{\circ}$ for at least $24 \mathrm{~h}$ without loss of nicotinamide nucleotides.

The concentration of $\mathrm{N}^{1}$-methyl nicotinamide in urine was measured by the small-scale modification of the fluorimetric method of Carpenter \& Kodicek (1950) that has been described previously (Bender, 1980 b). Urinary excretion of kynurenine was measured colorimetrically (Joseph \& Risby, 1975) after separation by ion-exchange column chromatography (Satoh \& Price, 1958). The plasma concentration of tryptophan and the tryptophan content of the diet after alkaline hydrolysis were determined by the norharman fluorescence method (Denckla \& Dewey, 1967).

The activities of the following enzymes were determined in samples of liver, by methods that have been described previously (Bender, 1980a): tryptophan oxygenase (Ltryptophan:oxygen oxidoreductase (decyclizing), EC 1.13.11.11), kynureninase (Lkynurenine hydrolase, $E C$ 3.7.1.3), 3-hydroxyanthranilic acid oxidase (3-hydroxyanthranilate:oxygen 3,4-oxidoreductase (decyclizing), EC 1.13.11.6), quinolinate phosphoribosyltransferase (nicotinate nucleotide: pyrophosphate phosphoribolsyltransferase (carboxylating), EC 2.4.2.19) and kynurenine 3-hydroxylase (L-kynurenine, NADPH: oxygen oxidoreductase (3-hydroxylating), EC 1.14.13.9) by the method of Bender \& McCreanor (1982). Theactivity of picolinatecarboxylase (aminocarboxymuconatesemialdehyde decarboxylase, $E C 4$.1 1. 1.45) was measured in kidney homogenates (Bender, 1980 a). For the studies of enzyme inhibition, L-kynurenine was added to the incubation buffer to a final concentration of $7.6 \mathrm{mmol} / 1$ and enzyme preparations were pre-incubated with leucine for $10 \mathrm{~min}$ before the reaction was initiated by the addition of substrate.

\section{RESULTS}

Animals receiving all three diets without the addition of excess leucine grew at the same rate throughout the 7-week period of the experiment, from a mean $( \pm S D)$ initial weight of $50 \pm 5 \mathrm{~g}$ at weaning to $85 \pm 7 \mathrm{~g}$ at 7 weeks. This is a considerably lower rate of growth than is observed with the same strain of rats fed on animal-house stock diet and reflects the fact that all three diets were formulated to be limiting in tryptophan and niacin, as well as being relatively low in protein. Animals fed on the diets to which $15 \mathrm{~g}$ leucine $/ \mathrm{kg}$ diet had been added grew at the same rate as control animals for the first 3 weeks, and thereafter gained a little weight, so that after 7 weeks their mean ( $\pm \mathrm{SD}$ ) weight was $70 \pm 5 \mathrm{~g}$. The food intake of animals receiving the leucine-supplemented diets was approximately $80 \%$ of that of the control animals. 
Table 3. The effects of added leucine $(7.6 \mathrm{mmol} / \mathrm{l})$ on the activities (nmol product formed/ min per $g$ tissue) of enzymes of tryptophan - nicotinamide nucleotide metabolism

(Mean values with their standard errors for five determinations)

\begin{tabular}{|c|c|c|c|c|}
\hline \multirow{2}{*}{$\begin{array}{l}\text { Treatment } \\
\text { Enzyme }\end{array}$} & \multicolumn{2}{|c|}{ Control } & \multicolumn{2}{|c|}{$+7.6 \mathrm{mmol}$ leucine $/ \mathrm{l}$} \\
\hline & Mean & SEM & Mean & SEM \\
\hline \multicolumn{5}{|c|}{ Tryptophan oxygenase (L-tryptophan: oxygen oxidoreductase (decyclizing), EC 1.13.11.11) } \\
\hline \multicolumn{5}{|c|}{$\begin{array}{l}\text { Kynurenine 3-hydroxylase (L-kynurenine, NADPH: oxygen oxidoreductase (3-hydroxylating), } \\
E C \text { 1.14.13.9) }\end{array}$} \\
\hline & $20 \cdot 3$ & 0.29 & $20 \cdot 6$ & 0.51 \\
\hline \multirow{2}{*}{\multicolumn{5}{|c|}{ Kynureninase (L-kynurenine hydrolase, EC 3.7.1.3) }} \\
\hline & & & & \\
\hline \multicolumn{5}{|c|}{ Picolinate carboxylase (aminocarboxymuconate-semialdehyde decarboxylase, $E C 4.1 .1 .45$ ) } \\
\hline \multicolumn{5}{|c|}{$\begin{array}{l}\text { Quinolinate phosphoribosyltransferase (nicotinate nucleotide:pyrophosphate } \\
\text { phosphoribosyltransferase (carboxylating), } E C \quad 2.4 .2 .19 \text { ) }\end{array}$} \\
\hline & 0.52 & 0.021 & 0.51 & 0.029 \\
\hline
\end{tabular}

Mean values were significantly different from control values $(t$ test $):{ }^{* *} 0.05 \geqslant P \geqslant 0.01$.

As can be seen from Table 2, the addition of $15 \mathrm{~g}$ leucine $/ \mathrm{kg}$ diet led to a significant reduction in the liver and blood concentrations of nicotinamide nucleotides in animals fed on diets in which tryptophan was a major or the only source of nicotinamide nucleotides (diets $\mathbf{A}$ and $\mathrm{C}$ ). In the animals fed on diet $\mathrm{B}$, which provided minimally adequate nicotinamide, the addition of leucine had no effect on blood nucleotides and caused a slight increase in the concentration in the liver.

The urinary excretion of $\mathrm{N}^{1}$-methyl nicotinamide was increased in animals receiving diet A together with an excess of leucine, and reduced in those animals receiving diet $\mathrm{C}$ with leucine. The addition of leucine to diet $\mathbf{B}$ had no effect on the urinary excretion of this nicotinamide metabolite.

Table 3 shows the effects of adding leucine to a final concentration of $7.6 \mathrm{mmol} / \mathrm{l}$ (an unphysiologically high concentration) to the incubation buffer on the activities of enzymes of tryptophan and nicotinamide nucleotide metabolism. Leucine caused activation of tryptophan oxygenase and inhibition of kynureninase. The inhibition of kynureninase was primarily competitive with respect to the substrate, with an increase in the Michaelis constant $\left(K_{m}\right)$ from $220 \mu \mathrm{mol} / 1$ in the absence of leucine to $660 \mu \mathrm{mol} / 1$ in the presence of $10 \mathrm{mmol} \mathrm{L}$-leucine/l. The activities of the other enzymes measured were unaffected by the addition of leucine.

There was no significant effect on the activities of any of the enzymes measured of feeding leucine-enriched diets. However, there was evidence of reduced activity of kynureninase in the animals fed on high-leucine diets; the mean ( \pm SE) excretion of kynurenine by animals fed on diet $\mathrm{C}$ was $14.1 \pm 1.8 \mathrm{mmol} / \mathrm{mol}$ creatinine, while the excretion in animals fed on diet $\mathrm{C}$ with $15 \mathrm{~g}$ leucine $/ \mathrm{kg}$ diet was $18.9 \pm 2 \cdot 1(P<0 \cdot 001)$. The addition of leucine to the diet had no effect on the plasma concentration of tryptophan.

\section{DISCUSSION}

The aim of this study was to determine whether a dietary excess of leucine is pellagragenic, as suggested by Gopalan \& Srikantia (1960) or not, as suggested by Nakagawa et al. (1975) 
and Manson \& Carpenter $(1978 a, b)$. In animals receiving diet $\mathrm{A}$, which provided for nicotinamide nucleotide synthesis from both tryptophan and nicotinamide, but not adequately from either precursor alone, and diet $\mathrm{C}$, which provided only tryptophan, the addition of $15 \mathrm{~g}$ leucine $/ \mathrm{kg}$ diet led to a significant reduction in the concentration of nicotinamide nucleotides in blood and liver. In animals receiving diet $\mathbf{B}$, which provided minimally adequate nicotinamide to meet requirements, the addition of leucine to the diet had no effect on the blood concentration of nicotinamide nucleotides, and led to a slight increase in the concentration in the liver. It thus appears that in animals that are reliant wholly or in part on synthesis of nicotinamide nucleotides from tryptophan, the addition of leucine to the diet in excess of requirements for protein synthesis is indeed pellagragenic. In animals fed on diet $A$, this effect was apparent as early as 4 weeks after the beginning of the experiment (preliminary observations), but there was no significant difference until the animals had received the diets for 7 weeks. The experiments with the other diets were therefore designed to measure the nucleotides after 7 weeks, as shown in Table 2.

Manson \& Carpenter $(1978 a, b)$ were unable to demonstrate any effect of a dietary excess of leucine on the rate of growth or the excretion of $\mathrm{N}^{1}$-methyl nicotinamide in rats, chicks or dogs. In the present study the addition of leucine to diet A, in which both tryptophan and nicotinamide were provided as precursors of the nucleotides, led to a small but significant increase in the urinary excretion of $\mathrm{N}^{1}$-methyl nicotinamide. A similar increase in the excretion of this nicotinamide metabolite was observed by Gopalan \& Srikantia (1960) in response to feeding a dose of $5 \mathrm{~g}$ leucine to human volunteers. They suggested that a daily intake of $5 \mathrm{~g}$ excess leucine would lead to a loss equivalent to $3.5 \mathrm{mg}$ niacin daily. In those animals that received diet $\mathrm{C}$, the addition of leucine caused a reduction in the urinary excretion of $\mathrm{N}^{1}$-methyl nicotinamide, as would be predicted by the reduced blood and liver contents of nicotinamide nucleotides. Urinary excretion of $\mathbf{N}^{1}$-methyl nicotinamide is generally accepted as an index of niacin nutritional status (Gontzea et al. 1976), but from the present study it would appear that either it is not adequately sensitive to differentiate between minimal adequacy and marginal deficiency, or it is subject to distortion caused by changes in the rate of turnover of nicotinamide nucleotides as a result of feeding an excess of leucine. Joubert \& de Lange (1962) also considered that the excretion of $\mathrm{N}^{1}$-methyl nicotinamide was an inadequate index of niacin nutrition, and proposed that $\mathrm{N}^{1}$-methyl nicotinamide: methyl pyridone carboxamide (the onward oxidation product of $\mathrm{N}^{1}$-methyl nicotinamide) was a more sensitive index for use in human studies. The strain of rats used in the present study did not excrete any significant amount of methyl pyridone carboxamide even after the administration of a loading dose of tryptophan (B. I. Magboul, unpublished results), and therefore no attempt was made to measure the excretion of this metabolite.

The results in Table 2 suggest that the most sensitive index of niacin nutritional status may be the blood concentration of total nicotinamide nucleotides; this is a functional pool of the metabolically active derivative of the vitamin and, unlike plasma concentrations of vitamins themselves, is unlikely to be distorted by a recent meal or other extraneous factors. The assay procedure used here to measure the blood concentration of the nucleotides seems to be readily adaptable to clinical studies, and may also be applicable in field studies, since it is possible to perform simple operations (addition of two stable reagents and boiling) and thus obtain a sample in which the nucleotides are stable at $4^{\circ}$ for at least $24 \mathrm{~h}$. Furthermore, the amount of blood required, $200 \mu \mathrm{l}$, can readily be obtained by finger prick.

Animals receiving the high-leucine diets grew less well than did control animals, and also ate less. It is not possible to determine whether the lower food consumption was a cause or consequence of the lower rate of growth and lower body-weight. However, although the lower rate of growth and lower food intake are confounding factors in interpreting the results, they do not seem to be related to the effects of leucine on nicotinamide nucleotide 
synthesis; a similar extent of growth retardation was observed in animals fed on diet B with added leucine, yet this had no effect on nicotinamide nucleotides. It is likely that the growth retardation was a general effect of a diet in which there was an imbalance in the intake of essential amino acids, and over-all a relatively low total intake of protein, as discussed by Harper et al. (1970). Presumably the depletion of tissue concentrations of nicotinamide nucleotides observed in this study was not, in itself, sufficiently severe to affect growth.

The results in Table 2 show that a dietary excess of leucine may be pellagragenic when the animals are reliant on tryptophan wholly or in part for the synthesis of nicotinamide nucleotides, but when there is an adequate amount of nicotinamide in the diet leucine has no effect. Yamada et al. (1979) also showed that a relatively large amount of leucine $(50 \mathrm{~g} / \mathrm{kg}$ diet) decreased the concentrations of nicotinamide nucleotides in tissues in animals that were receiving a low-protein diet and no preformed niacin, but had no effect when the diet provided adequate niacin. It is therefore obvious that leucine or a metabolite inhibits one or more of the enzymes of tryptophan-nicotinamide nucleotide metabolism, but has no effect on the activity of the enzymes involved in the utilization of preformed niacin. Table 3 shows that the addition of a relatively high concentration of leucine inhibits kynureninase competitively with respect to the substrate. This means that if such a concentration of leucine were achieved in the liver, it might be expected to reduce the flux of metabolites through the tryptophan oxidative pathway and hence reduce the rate of synthesis of nicotinamide nucleotides from tryptophan. The formation of quinolinic acid from acroleylaminofumarate (aminocarboxymuconic-semialdehyde) is a non-enzymic reaction, in competition with the enzymic decarboxylation of the substrate to aminomuconic-semialdehyde, catalysed by picolinate carboxylase. This means that a reduction in the flux of metabolites through the pathway will have a disproportionately large effect on the rate of quinolinic acid formation (Ikeda et al. 1965). Similarly, an increase in the activity of picolinate carboxylase will also reduce the formation of quinolinic acid; no such effect was observed in this study, but Ghafoorunissa \& Narasingha Rao (1973) have reported an increase in the activity of picolinate carboxylase in response to feeding $30 \mathrm{~g}$ leucine $/ \mathrm{kg}$ diet in excess of requirements.

There was no difference in the activity of kynureninase in livers from animals fed leucine-enriched diets compared with the control animals. This is presumably the result of the nature of the inhibition, a reversible competitive effect, and the method used to measure the activity of the enzyme, in which there was some dilution of the tissue on homogenization and hence dilution of the inhibitor, as well as the use of a saturating concentration of kynurenine as substrate which would therefore reverse the inhibition. The increased urinary excretion of kynurenine by animals receiving a leucine-enriched diet suggests that in vivo there is reduced activity of kynureninase as a result of feeding an excess of leucine and, therefore, a high enough concentration of leucine to be inhibitory must occur under these conditions.

It is difficult to determine the physiological significance of the increased activity of tryptophan oxygenase in the presence of leucine. This presumably reflects an interaction at the relatively unspecific 'activator' site of the enzyme (Greengard \& Feigelson, 1961). An increase of approximately $75 \%$ in the activity of this enzyme is within the normal range of diurnal variation and response to hormone secretion and stress. There was no effect of feeding high-leucine diets on the concentration of tryptophan in plasma, whereas if there was a marked increase in the activity of tryptophan oxygenase, it would be expected that the plasma concentration of tryptophan would fall. However, even a relatively small increase in the activity of tryptophan oxygenase may result in kynureninase activity becoming the limiting factor in the over-all rate of tryptophan metabolism (Knox, 1953). Hence inhibition of kynureninase, either directly as observed here or indirectly as the result 
of changes in the distribution of the cofactor pyridoxal phosphate, due to induction of leucine aminotransferase (Krishnaswamy \& Bapu Rao, 1978) could reduce the rate of tryptophan metabolism to nicotinamide nucleotides considerably.

Ghafoorunissa \& Narasingha Rao (1973) and Krishnaswamy \& Bapu Rao (1978) have demonstrated that in response to the addition of $30 \mathrm{~g}$ excess leucine $/ \mathrm{kg}$ diet there is an increase in the complete oxidation of tryptophan, due to increased activity of picolinate carboxylase and reduced activity of quinolinate phosphoribosyltransferase, both of which will lead to reduced synthesis of nicotinamide nucleotides from tryptophan. In the present study we have demonstrated that a less severe excess intake of leucine $(15 \mathrm{~g} / \mathrm{kg}$ diet $)$ affects principally the activity of kynureninase. We have thus confirmed the hypothesis of Gopalan \& Srikantia (1960) that when intakes of tryptophan and niacin are only marginally adequate, and there is considerable reliance on synthesis of nicotinamide nucleotides from tryptophan, even a modest excess of leucine in the diet may be a precipitating factor in pellagra.

B.I.M. was in receipt of a studentship from the Agricultural Development Corporation of the Democratic Republic of the Sudan.

\section{REFERENCES}

Bapu Rao, S., Raghuram, T. C. \& Krishnaswamy, K. (1975). Nutr. Metab. 18, 318.

Belavady, B. \& Udayasekhara Rao, P. (1973). Int. J. Vit. Nutr. Res. 43, 454.

Belavady, B. \& Udayasekhara Rao, P. (1979). Ind. J. Exp. Biol. 17, 659.

Bender, D. A. (1980a). Biochem. Pharmacol. 29, 707.

Bender, D. A. (1980b). Biochem. Pharmacol. 29, 2099.

Bender, D. A. \& McCreanor, G. M. (1982). Biochim. Biophys. Acta 717, 56.

Bender, D. A., Magboul, B. I. \& Wynick, D. (1982). Br. J. Nutr. 48, 119.

Carpenter, K. J. \& Kodicek, E. (1950). Biochem. J. 46, 421.

Carter, E. G., Hurrell, R. F. \& Carpenter, K. J. (1977). Proc. Nutr. Soc. 36, 107A.

Denckla, W. D. \& Dewey, H. K. (1967). J. Lab. Clin. Med. 69, 160.

Ermolieff, S. \& Grosshaus, E. (1979). Ann. Dermatol. Vénéreol. 106, 591.

Ghafoorunissa \& Narasingha Rao, B. S. (1973). Biochem. J. 134, 425.

Gontzea, I., Rujinski, A. \& Sutzesco, P. (1976). Biblio. Nutr. Dieta. 23, 95.

Gopalan, C., Belavady, B. \& Krishnamurthy, D. (1969). Lancet ii, 956.

Gopalan, C. \& Srikantia, S. G. (1960). Lancet i, 954.

Greengard, O. \& Feigelson, P. (1961). J. biol. Chem. 236, 158.

Harper, A. E., Benevenga, N. J. \& Wohlhuetter, R. M. (1970). Physiol. Rev. 50, 428.

Ikeda, M., Tsuji, H., Nakamura, S., Ichiyama, A., Nishizuka, Y. \& Hayaishi, O. (1965). J. biol. Chem. $240,1395$.

Joseph, M. H. \& Risby, D. (1975). Clin. Chim. Acta 63, 197.

Joubert, C. P. \& de Lange, D. J. (1962). Proc. Nutr. Soc. Southern Africa 3, 60.

Kaplan, N. O., Colowick, S. P. \& Barnes, C. C. (1951). J. biol. Chem. 191, 461.

Knox, W. E. (1953). Biochem. J. 53, 379.

Krishnaswamy, K. \& Bapu Rao, S. (1978). Br. J. Nutr. 39, 61.

Lowry, O. H., Passoneau, J. V. \& Rock, H. K. (1961). J. biol. Chem. 236, 2756.

Manson, J. A. \& Carpenter, K. J. (1978a). J. Nutr. 108, 1883.

Manson, J. A. \& Carpenter, K. J. (1978b). J. Nutr. 108, 1889.

Nakagawa, I., Ohguri, S., Sasaki, A., Kajimoto, M., Sasaki, M: \& Takahashi, T. (1975). J. Nutr. 105, 1241.

Satoh, K. \& Price, J. M. (1958). J. biol. Chem. 230, 781.

Yamada, O., Shin, M., Sano, K. \& Umezawa, C. (1979). Int. J. Vit. Nutr. Res. 49, 376. 